\title{
Saúde da população negra: A religiosidade afro-brasileira e a saúde pública
}

\author{
Black people's health: African-Brazilian religiosity and public health
}

Sônia Regina Corrêa Lages

Psicóloga, Pós-Doutora em Psicossociologia de Comunidades e Ecologia Social, professora adjunta do Departamento de Psicologia da Universidade Federal de Minas Gerais (UFMG), Belo Horizonte, MG - Brasil, e-mail: sonialages@ig.com.br

Recebido: 29/06/2011 Received: 06/29/2001

Aprovado: $17 / 08 / 2011$ Approved: 08/17/2011

\section{Resumo}

0 presente trabalho trata de uma pesquisa que procurou identificar no discurso de lideranças da religião afro-brasileira da Umbanda, elementos capazes de transferir saberes desse universo religioso para o campo político da saúde pública. A Umbanda abarca, em sua grande maioria, coletivos da população negra que procuram tratamento e cura nos saberes das entidades do Preto-Velho, representante da diáspora negra no Brasil. Tais identidades foram submetidas à lógica da colonialidade do poder - hegemonia eurocêntrica do conhecimento, que conseguiu silenciar sociedades que não foram ouvidas na produção do conhecimento. No entanto, sistemas marginais de pensamento foram construídos no espaço colonial, denominado por Mignolo de pensamento liminar. Diante disto, e a partir de um quadro conceitual definido pelos pensadores dos Estudos Culturais, as narrativas dos chefes-de-terreiro são analisadas objetivando identificar elementos viabilizadores de um canal de interlocução entre essas lideranças e os gestores e profissionais de saúde, com a finalidade de constituição de novas redes de apoio e cuidados à saúde. A metodologia de pesquisa fez uso da entrevista semiestruturada e da análise do discurso como ferramenta de exame das narrativas apoiada nos conceitos de Sociologia das ausências e da tradução cultural de Boaventura Santos. 0 trabalho conclui apontando as possibilidades e limites da tradução cultural entre os diferentes campos. Se por um lado eles convergem no sentido da integralidade, por outro, existe o perigo das aproximações de saberes em situações de desigualdade de poder, que podem levar à construção de novas hegemonias culturais.

Palavras-chave: Umbanda. Preto-velho. Saúde pública. Tradução cultural.

\section{Abstract}

This paper exposes a research that aimed to identify, in the discourse of African-Brazilian religion Umbanda's leadership, elements which enable knowledge transference from this religious realm into the political field of public health. Umbanda encompasses, in its majority, groups of black people who seek treatment and healing under the knowledge of the "Preto-Velho" spiritual entities, representative of the black diaspora in Brazil. Such entities were subjected to the colonial logics of power - an eurocentric hegemony of the knowledge, which was able to silence societies that had not been heard as to the production of knowledge. Nevertheless, marginal systems of thought 
were built within the colonial environment, called by Mignolo "liminar thought". In this sense, and from the conceptual framework defined by Cultural Studies scholars, the "terreiro" chiefs' narratives are analyzed to identify elements that make a channel of communication between those leaderships and public health managers and workers viable, to build new networks for support and care of health. The research methodology used semi-structured interview and discourse analysis as tools to analyze the narratives based on Boaventura Santos' concepts of "sociology of absences" and "cultural translation". The paper ends with considerations about possibilities and limits of cultural translation among the different fields. If, on one hand, they converge in the direction of wholeness, on the other, there is the risk that knowledge convergence may lead to the building of new cultural hegemonies in situations of power inequality.

Keywords: Umbanda. Preto-velho. Public health. Cultural translation.

\section{Introdução}

Estudos quantitativos documentam os impactos da iniquidade na saúde de determinados segmentos da população, em que classe socioeconômica, gênero, raça/etnia e idade se apresentam como determinantes da saúde e da doença. No caso da população negra brasileira, sabe-se que esta sofre um acúmulo de desigualdades - socioeconômicas e raciais -, reforçadas pelo racismo institucional, que foi oficialmente reconhecido pelo Ministério da Saúde quando da realização do II Seminário Nacional de Saúde da População Negra, em 2007. Figueroa define o racismo institucional como

o fracasso coletivo de uma organização em prover um serviço profissional e adequado às pessoas com certos marcadores grupais de cor, cultura origem étnica ou regional. 0 que caracteriza esse tipo de racismo é que ele extrapola as relações interpessoais e ocorre à revelia das boas intenções individuais, implicando o comprometimento dos resultados de planos e metas de instituições, gestões administrativas e de governo (Figueroa, 2004, p. 28).

0 racismo institucional afeta muitas das dimensões de sua existência, provocando situações de opressão, exclusão, discriminação socioeconômica, o que a coloca numa situação de maior vulnerabilidade diante de uma série de agravos que contribuem para com o comprometimento da saúde. Essas desigualdades se refletem nos dados epidemiológicos que evidenciam diminuição da qualidade e da expectativa de vida da população negra, tanto pelas altas taxas de morte materna e infantil, mortalidade por causas externas, diabetes, câncer no colo do útero, dentre outras. (Ministério da Saúde - Política Nacional de Saúde Integral da População Negra, 2007).

No entanto, se hoje as formas de adoecer e morrer retratam as condições materiais e sociais como local da moradia, condições de trabalho, ocupação e renda, acesso a escolas, qualidade de atenção por parte dos serviços e profissionais de saúde (Oliveira, 2002) a que está submetida a população afrodescendente no Brasil, a história da saúde e das doenças da população negra mostram que essa configuração é decorrente do processo histórico de escravidão que ocorreu no Brasil.

Naquele momento, as práticas cotidianas para tratamento da saúde e que portavam uma determinada concepção de doença e de corpo se confrontavam com o descaso e a ineficiência dos tratamentos da medicina da época, tendo destaque a dimensão religiosa, o apelo aos santos, às orações, às simpatias e o conhecimento a respeito do uso medicinal das plantas. Isto levava a população a procurar outros meios de tratamento de saúde permeados pelas crenças nos orixás africanos, nos espíritos de antepassados, nos rituais de possessão, no uso das plantas e amuletos. Tais crenças e práticas estão ainda hoje presentes no campo das religiões afrodescendentes, que recebe diferentes denominações conforme sua localização geográfica: Candomblé e Umbanda (presentes em todos os estados brasileiros), Tambor de Mina (Maranhão), Pajelança (Amazônia), Terecô (Maranhão), Encantaria (Piauí e Maranhão), Batuque (Rio Grande do Sul), Omoloko (Rio de Janeiro, Minas e São Paulo), dentre outros. 
Na tradição africana, o processo saúde-enfermidade é concebido a partir de uma visão holística alicerçada em uma cosmovisão mítica e religiosa que sacraliza a relação dos seres humanos com a natureza (Augras, 2003; Ferretti, 2003; Guimarães, 1990; Marmo, 2007; Montero, 1985, dentre outros). No entanto, no Brasil, apesar dessa arte de cuidar e promover a saúde serem centenárias, ela não recebe a atenção devida do sistema de saúde. Mas uma proposta de atenção à saúde afrodescendente no Brasil,

[...] passa, necessariamente, pelo resgate, desestigmatização e valorização dos saberes médicos de matriz africana, urgindo potencializar tais espaços enquanto polos de difusão dos conhecimentos sobre saúde da população negra e de suas respectivas práticas preventivas, pois são locais que gozam da confiança da população negra, portanto podem ser alavancados à condição de centros de educação popular em saúde, já que tradicionalmente são locais de prevenção e cura das doenças (Oliveira, 2002, p. 200).

Se a atenção à saúde no sistema público ainda está longe de, na prática, valorizar tais espaços como sendo de saberes, essa necessidade está registrada nos documentos:

1) A saúde da População Negra e o SUS - Ações afirmativas para avançar na equidade (Ministério da Saúde, 2005);

2) Política Nacional de Humanização do SUS PNHSUS;

3) Estratégias da OMS sobre Medicina Tradicional 2002-2005 (OMS, 2002);

4) Estratégias de Municípios e Comunidades Saudáveis - MCS.

A partir desse contexto, e considerando a Saúde da População Negra como um conjunto de estudos, pesquisas e propostas de atenção à saúde (Oliveira, 2001) é que o presente trabalho, destacando o campo religioso da Umbanda, tem a finalidade de levantar as possibilidades de uma tradução cultural de saberes acerca do processo saúde e doença, no sentido colocado por Boaventura Santos (2008), o de um diálogo que visa a superação da ideia de uma teoria geral que explique toda a realidade. Nessa direção, todo conhecimento é considerado parcial e, portanto, sujeito à complementaridade. 0 exercício da tradução objetiva expandir a inteligibilidade recíproca, sem destruir a identidade dos parceiros, criando, nas práticas ou estratégias, nos discursos ou saberes, uma zona de contato capaz de os tornar porosos, e, assim, permeáveis a outros discursos, saberes e práticas. 0 exercício, pois, da tradução tem como foco a identificação e reforço do que é comum na diversidade, sem suprimir o que separa esses entendimentos.

$\mathrm{Na}$ linha dessa proposta, os terreiros das religiões afro-brasileiras são considerados como territórios que abrigam conhecimentos e práticas ancestrais, que atendem a um conjunto de diferentes grupos sociais que buscam tratamento para suas doenças físicas, psíquicas e espirituais. 0 diálogo com a saúde pública - gestores e profissionais dos centros de saúde -, pode propiciar a ampliação dos espaços de atenção à saúde, minorizando as desigualdades em saúde. Os terreiros podem incluir no exercício de suas terapêuticas, o apoio aos serviços públicos de saúde, por meio da educação em saúde (informações a respeito das doenças que afetam de forma mais pontual a população afrodescendente, seja por fatores genéticos ou sociais, a pobreza e o racismo). Nessa busca pelas zonas de contato, as unidades básicas de saúde e centros de saúde podem se abrir para o conhecimento acerca das terapêuticas realizadas no terreiro de forma a superar os preconceitos com relação às religiosidades afro-brasileiras. Isso se torna uma ação afirmativa de combate ao preconceito cultural, assim como inclui tais religiosidades nos debates sobre a saúde junto à comunidade do entorno, o que mobiliza a participação e controle social da saúde. Esse diálogo se justifica pela necessidade de o SUS ampliar sua atuação em prol da promoção da saúde que atinge de forma mais específica a população negra como a anemia falciforme, DSTs, a hanseníase, tuberculose e hepatite viral.

É, então, nesse sentido que caminha o presente trabalho, o de buscar os elementos que viabilizam a tradução cultural, o que potencializa os terreiros como importantes agências de saúde cujas ações sociais atingem um considerado contigente social que sofre as consequências das desigualdades sociais no país.

Tais elementos, que integram as zonas de contato, se referem aqui à concepção das lideranças umbandistas sobre a concepção do processo saúde-doença e as terapêuticas utilizadas pelos terreiros, e os objetivos do SUS quanto à integralidade em saúde. 


\section{Procedimentos metodológicos}

Trata-se de uma pesquisa orientada pelos pressupostos teórico-metodológicos qualitativos, realizada a partir de entrevistas semiestruturadas e que utilizou a análise do discurso como ferramenta para a análise dos textos. Tal ferramenta é amparada pelas posições de Boaventura Santos (2008) que propõe uma nova postura metodológica que se refere a um conjunto de epistemologias que partem da diversidade e da globalização contra-hegemônica e pretendem contribuir para credibilizar e fortalecer conhecimentos que se assentam no pressuposto da existência de um sujeito que possui uma episteme própria de conhecer e traduzir a realidade, independente das visões e práticas da ciência moderna.

As lideranças entrevistadas dirigem centros de Umbanda localizados em bairros de periferia da cidade de Juiz de Fora, MG: Templo Umbandista Luz do Oriente (Santa Luzia); Centro Espírita Senhora das Águas (Industrial); Tenda Espírita Cabana Pai Jacob (Caeté); Centro Espírita Pai Antônio (Santo Antônio).

\section{Os terreiros de Umbanda como territórios promoto- res de saúde}

O conceito moderno de doença guiado pelo modelo biomédico desvincula o indivíduo das suas crenças e visões de mundo, de sua espiritualidade, da relação com a natureza, do seu sofrimento psicossocial perante a uma série de eventos cotidianos como o trabalho, o amor, o lazer, as relações sociais. 0 espaço privilegiado para atendimento a esse sujeito isolado de si e do mundo, torna-se o hospital que se transforma no dispositivo essencial para a produção e transmissão do conhecimento da medicina (Foucault, 1979).

A perspectiva médica oficial confisca do doente sua autonomia quanto à sua recuperação, uma vez que essa responsabilidade é colocada nas mãos do médico e da próspera indústria farmacêutica. A intervenção médica tradicional fornece ao indivíduo uma explicação experimental dos mecanismos químico-biológicos da morbidez e dos meios para controlá-los. Assim, existe um constante esforço para estabelecer uma ligação entre um complexo patológico - o doente ou o órgão, e um complexo terapêutico - o tratamento adequado que deve ser prescrito (Laplatine, 2004).

As doenças físicas são tratadas por meio de terapias que agridem outros órgãos do corpo e muitas vezes se traduzem em intervenções brutais, provocadoras de efeitos colaterais, podendo se tornar, às vezes, mais graves que a própria doença que se procurava tratar. Esse modelo, assentado, fundamentalmente, no reducionismo biologista ocasionou uma hiperespecialização e uma medicalização da sociedade, incapacitando-o de tratar a pessoa incluindo suas relações sociais. A negação do social e do humano, aspectos que estão compreendidos nos sinais e sintomas, possibilita o médico explicar o "como", mas não o porquê". E é justamente o "porquê" que faz parte da demanda do doente, ele é uma exigência de explicação totalizante e subjetivante da pessoa em questão.

A procura, por parte do indivíduo, sobre o "porquê" de seu adoecimento faz com que ele busque outros espaços que veiculam diferentes concepções de doença, saúde, corpo e tratamento e que se configuram numa série de práticas cotidianas e populares que apresentam uma forma própria de interpretar o adoecimento. Tais práticas acabam se reproduzindo no interior dos grupos sociais, ou de forma mais organizada em outros espaços, constituídos por um conjunto de conhecimentos com relação ao corpo, que são disponibilizados para a comunidade, como é o caso da religião. Essas crenças e práticas conferem sentido ao adoecimento, ele possui um significado que se relaciona com as relações entre os indivíduos, a sociedade e o divino. Podem significar a expiação por uma culpa individual ou social, uma missão a cumprir uma provação de Deus. Essa forma de perceber a doença traz consequências psicológicas que promovem uma reordenação da vida, hábitos cotidianos e relações, eleva a autoestima, acalma, confere qualidade de vida e leva a pessoa à aceitação da morte de forma mais pacífica.

Dentre esses espaços, destacam-se as religiões afro-brasileiras, que, por meio de várias denominações - Tambor de Mina, Tambor de Caboclo, Umbanda, Candomblé, Jurema, Batuque, Encantaria, etc -, espalham-se por diferentes regiões do país, atuando como núcleos de resistência da cultura negra, realizando seus rituais no denominado terreiro.

E é justo nesse espaço sagrado que a presença de espíritos ancestrais, mediante possessão, que pode ser compreendida como a memória da história de opressão que marcou corpos, subjetividades e identidades de uma grande parcela da população brasileira, possui novamente essa história e a reconta de maneira diferente, inaugurando um outro saber. 


\section{Tradução cultural: possíveis diálogos entre os campos de saberes afro-brasileiros e o do SUS}

Mignolo, no seu esforço para reinterpretar a colonização da América, a partir dos saberes subalternos e do pensamento liminar, coloca que a conexão do Mediterrâneo com o Atlântico, por meio de um novo circuito comercial a partir do século XVI, lançou as fundações tanto da modernidade como da colonialidade. Esse novo circuito também criou condições para um novo imaginário global construído a partir da ideia de que as novas terras "descobertas" (inicialmente denominadas de "Indias Occidentales") eram uma extensão da Europa. A construção do ocidentalismo, que incluiu as Américas no projeto de expansão do capital e que também acabou por expandir uma colonização intelectual eurocêntrica, se tornou possível com a colonialidade do poder que configurou uma geopolítica do conhecimento, na qual teorizar, pensar, é privilégio de poucos indivíduos, localizados em determinados lugares geohistóricos do globo.

O autor lança mão de Darcy Ribeiro em sua argumentação sobre o desprezo dos saberes que foram subjugados pela estrutura da colonialidade do poder:

Do mesmo modo que a Europa levou várias técnicas e invenções aos povos presos em sua rede de dominação...ela também os familiarizou com seu equipamento de conceitos, preconceitos e idiossincrasias, referentes simultaneamente à própria Europa e aos povos coloniais. Os colonizados, privados de sua riqueza e do fruto de seu trabalho sob a dominação colonial, sofreram ademais, a degradação de assumir como sua a imagem que era um simples reflexo da cosmovisão europeia, que considerava os povos coloniais racialmente inferiores porque eram negros, ameríndios ou "mestizos". Mesmo as camadas mais inteligentes dos povos não europeus acostumaram-se a enxergar-se e a suas comunidades como uma infra-humanidade, cujo destino era ocupar uma posição subalterna pelo simples fato de que a sua era inferior à da população europeia (Ribeiro, 1968, p. 63 citado por Mignolo, 2003, p. 44-45).

Por colonialidade do poder, Mignolo entende, então, como a invisibilidade das formas de conhecimento anteriores ao projeto moderno, contando com o totalitarismo epistêmico teológico e científico. Neste mesmo sentido, Quijano (2005) defende que esse empreendimento foi possível na América a partir da ideia de raça que outorgou legitimidade às relações de dominação impostas pela conquista, ou seja, uma suposta estrutura biológica que situava uns em situação natural de inferioridade em relação aos outros. As relações sociais fundadas nessa categoria mental produziu novas identidades históricas: os índios, os negros, os mestiços, associando-as às hierarquias lugares e papéis sociais correspondentes na nova estrutura global de controle do trabalho. Não mais os astecas, os maias, os tupis, os tupinambás, mas os índios. Não mais os iorubás, os zullus, os bantos, os congos, mas os negros. Esse resultado da história teve duas implicações decisivas. A primeira, como diz Quijano (2005, p. 249), é óbvia: todos aqueles povos foram despojados de suas próprias identidades históricas. A segunda é que sua nova "identidade racial, colonial e negativa, implicava o despojo de seu lugar na história da produção cultural da humanidade". Isto implicava que dali por diante passaram a ser o passado, ou ainda, "o padrão de poder baseado na colonialidade implicava também um padrão cognitivo, uma nova perspectiva de conhecimento dentro da qual o não europeu era o passado e desse modo, inferior, sempre primitivo".

Nesse contexto, da colonialidade do poder, as novas identidades foram subsumidas pelo projeto da construção de uma identidade nacional e a força de tal empreendimento conseguiu silenciar sociedades que não foram e não são ouvidas na produção mundial do conhecimento. Mas esse silêncio imposto alcança uma estrutura perversa, pois ele circula dentro do próprio sul, utilizado a partir de Santos (2008), como metáfora do sofrimento humano. Tal silêncio é compreendido pelo autor como promovendo o epistemicídio, que desqualifica as epistemes provenientes das ancestralidades indígena e africana.

A superação desse silêncio, passa pela reinvenção da emancipação social, proposta por Santos (2008), pela sociologia das ausências, que explicita as experiências que foram invisibilizadas e desperdiçadas pelas monoculturas que, por diferentes modos, produziram a não existência. A sociologia das ausências denuncia, pois, as lógicas de produção do não existente:

a) a da monocultura do saber e do rigor do saber;

b) a da monocultura do tempo linear que constrói a história com um só sentido e única direção;

c) a da monocultura da naturalização das diferenças com a naturalização das hierarquias; 
d) a da monocultura do universal e do global, tornando irrelevante as demais escalas;

e) a da monocultura dos critérios de produtividade e de eficácia capitalista. Essas lógicas são produtoras de cinco qualificações: o ignorante, o residual, o inferior, o local e o improdutivo.

Quanto à monocultura do saber, “É o modo de não existência mais poderoso", pois tudo o que o cânone não reconhece ou legitima toma a forma de ignorância ou de incultura (Santos, 2008, p. 103). 0 confronto e o diálogo entre os saberes exige a substituição da monocultura do saber por uma ecologia dos saberes, mas num sentido que supera a ideia de que os saberes não científicos são alternativos ao saber científico. Considerando a biomedicina e medicina tradicional praticada na África, não faz sentido considerar essa última como alternativa à primeira. 0 importante "é identificar os contextos e as práticas que cada um opera e o modo como concebem a saúde e doença e como superam a ignorância (sob a forma de doença não diagnosticada) em saber aplicado (sob a forma de tratamento e cura) (Santos, 2008, p. 107).

A sociologia das ausências substitui a monocultura do tempo linear, concepção adotada pela modernidade ocidental a partir da secularização judaica-cristã, pela ecologia das temporalidades, "que visa a libertar as práticas sociais do seus estatuto de resíduo, restituindo-lhes a temporalidade própria, e assim, a possibilidade de um desenvolvimento autônomo" (Santos, 2008, p. 110). Uma vez que tais temporalidades são recuperadas e dadas a conhecer

as práticas e sociabilidades que por elas se pautam tornam-se inteligíveis e objetos credíveis de argumentação e de disputa política. Por exemplo, uma vez liberta do tempo linear e devolvida à sua temporalidade própria, [...] a presença ou relevância dos antepassados na vida dos indivíduos ou dos grupos sociais numa dada cultura deixa de ser uma manifestação anacrônica de uma religião primitiva ou de magia para passar a ser outra forma de experenciar o tempo presente (Santos, 2008, p. 110).

Se a sociologia das ausências revela as experiências que foram desperdiçadas, e que, apesar da produção da desqualificação, sobrevivem de forma marginalizada, o autor propõe uma outra epistemologia, a sociologia das emergências, que, calcada na ética do cuidado, é exercida em relação às alternativas possíveis. As duas sociologias estão estreitamente associadas, visto que, quanto maior for a diversidade e multiplicidade de experiências presentes, maiores as possibilidades de futuras novas ecologias, no sentido de que: não há ignorância geral nem conhecimento geral; as sociedades são constituídas de várias temporalidades; existe, sim é o reconhecimento da igualdade e da diferença; é possível a desglobalização e a reglobalização do local; e é viável a recuperação/valorização dos sistemas alternativos de produção e de organização popular.

Por sua vez, Mignolo discute essas outras formas de experienciar o tempo presente, como sistemas marginais de pensamento, que foram construídos no espaço colonial, e que ele denomina de pensamento liminar, caracterizado como fissuras, brechas encontradas no imaginário ocidental manipulado pela colonialidade do poder. A emergência do pensamento liminar é uma nova modalidade epistemológica que surge da interseção da tradição ocidental e a diversidade de categorias suprimidas sob o ocidentalismo; é uma outra lógica que valoriza outros tipos de conhecimento, reivindica a legitimidade e o lugar de onde são enunciados.

0 pensamento liminar surge a partir de uma razão subalterna que é a resposta à necessidade de repensar e reconceitualizar as histórias narradas e a conceitualização apresentada para dividir o mundo entre dicotomias - cristão-pagão, bárbaros-civilizados, desenvolvidos-subdesenvolvidos, todos eles projetos globais mapeando a diferença colonial.

A partir disto, o autor entende que um dos objetivos da teorização pós-ocidental/colonial seria a de reinscrever na história da humanidade, o que foi suprimido pela razão moderna, o de deslocar a imagem unificada da América, promovendo um lócus de enunciação que enfatiza a sobrevivência marginal das ruínas provocadas pela diáspora ameríndia e africana no início do período moderno.

A religião afrodescendente da Umbanda, desde sua constituição vem de forma resistente cumprindo esse objetivo colocado por Mignolo a partir do momento que integra em seu panteão todos os coletivos marginalizados pela colonialidade do poder por meio dos Pretos-velhos, Caboclos, crianças, e do Povo da Rua, representados pelos Exus e Pomba-giras. 0 panteão umbandista abriga a marginalidade social brasileira, compondo um grande texto cultural que fala da experiência da escravidão e da luta de um povo híbrido, demonstrando o que a colonialidade do poder não foi capaz de destruir. 
Inumeráveis entidades e identidades descem no terreiro de Umbanda mediante possessão: Pomba-giras francesas, espanholas, nordestinas; Pretos e Pretas-velhas de diferentes localidades da África; caboclos representando índios e os pobres nordestinos; boiadeiros; vagabundos desempregados. No terreiro, o intenso trânsito dos espíritos dribla os códigos morais e coloca juntos a Virgem Maria, Iemanjá e Pomba-gira. 0 médium, seja ele, mulher ou homossexual, só adquire seus status de um médium completo se for capaz de receber em seu corpo entidades masculinas, femininas, adultos, crianças, idosos, e de pessoas de todas as cores: negros, brancos, mestiços, amarelos. Esse festival de cores, sexualidades e gerações apontam para a compreensão de Hall (2003) sobre a cultura popular. Para ele, no caso das Américas, em que as sociedades são compostas de muitos povos, em que as origens não são únicas, mas diversas, e em que o vínculo com o colonizador não foi capaz de destruir por inteiro sua originalidade, os indivíduos passam a fazer parte de uma relação dialógica mais ampla com o "outro". Existe uma "zona de contato" (Hall, 2003, p. 31), um termo que se refere à interação, ao entrosamento das compreensões e práticas. Refere-se o autor a uma cultura híbrida, não no sentido de uma composição racial mista de uma população, ou de suas apropriações ou adaptações, mas no sentido de uma tradução cultural (Hall, 2003, p. 74). Tal conceito se refere a um processo de revisão que a cultura faz de seus valores de referência, negociados a partir da diferença com o outro. Para ele, "o essencial em uma cultura popular são as relações que colocam a "cultura popular" em uma tensão contínua (de relacionamento, influência antagonismo)" (Hall, 2003, p. 257). Na voz de Hall:

As estratégias de différance não são capazes de inaugurar formas totalmente distintas de vida (não funcionam segundo a noção de uma superação dialética totalizante). Não podem conservar intactas as formas antigas e tradicionais de vida. [...] Essas estratégias surgem nos vazios e aporias, que constituem sítios potenciais de resistência, intervenção e tradução. Nesses interstícios existe a possibilidade de um conjunto disseminado de modernidades vernáculas ( Hall, 2003, p. 61).

A partir da tradução cultural, as pessoas são obrigadas a negociar com as novas culturas em que vivem, não se deixando assimilar por elas, e não perdendo completamente suas identidades - traços culturais, linguagens, histórias particulares de vida, pelas quais foram marcadas (Hall, 2003).

A religião umbandista pode ser considerada, pois, como um tipo de compreensão da cultura que foge à concepção binária iluminista, que de um lado coloca os particularismos e as tradições, e do outro lado, o universalismo e a modernidade, tornando as fronteiras maleáveis, móveis, o que é a proposta por Stuart Hall $(2001,2003)$ para a compreensão da cultura popular.

A tradução cultural possibilita a emancipação social, pois amplia a consciência de incompletude de cada cultura envolvida no diálogo. Para Santos (2008, p. 123), a tradução "é o procedimento que permite criar inteligibilidade recíproca entre as experiências do mundo, tanto as disponíveis como as possíveis, reveladas pela sociologia das ausências e a sociologia das emergências.

Nesse procedimento, as experiências do mundo são observadas a partir das relações hegemônicas e do que está para além dela, sem, em nenhum momento, haver a redução de uma à outra. 0 trabalho da tradução visa a criar inteligibilidade e articulação na diversidade e na multiplicidade, podendo ocorrer tanto em termos dos saberes como das práticas sociais, contribuindo para com a definição dos potenciais contra-hegemônicos.

Nessa direção, pode-se afirmar que preocupações semelhantes com relação à saúde estão presentes no campo religioso da Umbanda e no campo do SUS. Os conceitos de integralidade do SUS têm muito o que aprender com a visão holística da Umbanda sobre a saúde e com o acolhimento do Preto-velho no terreiro, o que aponta para a possibilidade de uma cooperação entre os referidos campos.

A partir do campo das posições dos autores apresentados, é possível compreender essa expressão cultural afrodescendente como uma forma subterrânea de conviver com políticas impostas, instituídas.

0 conceito de integralidade do SUS está presente nos seguintes documentos: Estratégia da Organização Mundial de Saúde sobre Medicina Tradicional 2002-2005 (2002), Política Nacional de Práticas Integrativas e Complementares no SUS (2006) e Políticas de Humanização do SUS/Cadernos HumanizaSUS Formação e Intervenção (2010).

A integralidade é uma expressão que possui muitos sentidos, mas converge, quanto à contraposição, ao reducionismo, à fragmentação e objetivação dos sujeitos. 0 princípio da integralidade compreende 
que as necessidades das pessoas e dos grupos populacionais devem ser atendidas de uma maneira ampliada, o que ainda não é uma realidade. Pensar a integralidade é perceber o ser humano com suas especificidades em relação à cultura (Mattos, 2010). Isso significa que o atendimento deve ser voltado para sua saúde e não apenas para sua doença, ou seja, o órgão afetado, deve ser considerado o entorno do indivíduo, seus hábitos de vida.

A partir disto, e considerando o conceito de tradução cultural (Santos, 2008), a integralidade buscada pelo SUS tem a possibilidade de participar de um diálogo com as práticas realizadas nos terreiros em prol da saúde e prevenção das doenças a partir de elementos viabilizadores desse possível encontro, e que serão apresentados a seguir.

\section{A concepção do processo saúde-doença na cosmovisão umbandista}

A concepção de saúde e doença, veiculada no discurso das lideranças umbandistas, está assentada numa visão de cosmologia que integra o mundo dos vivos e o mundo dos mortos, a partir de um intenso e contínuo trânsito dos espíritos que retornam seja para ajudar e trazer saúde, alegria e paz às pessoas, seja para atormentá-las causando-lhes o adoecimento. Estes, denominados de obsessores, podem afetar o corpo do indivíduo, levando-o a sofrer de problemas emocionais, como a depressão, a melancolia.

Outras dimensões são acrescentadas e se referem às doenças, tendo como causas sociais: a falta de moradia, a falta de alimento, o desemprego. Não cabe ao terreiro resolver tais questões, mas cabe a orientação para que a pessoa busque soluções preparando-as psicologicamente para enfrentar situações de desânimo, redimensionando os problemas, colocando-os em um patamar em que o medo das situações não imobilize o indivíduo. Diz A. "Como é que a pessoa vai ter cura, se ela não tem onde morar? Como uma pessoa vai ter cura se ela não tem o que comer, se ela não tem trabalho?".

Os comportamentos e estilos de vida são também causadores de doenças psíquicas, o stress, a depressão, e acabam por adoecer o corpo físico, assim como questões subjetivas, pois é considerado o sofrimento que é causado pelos relacionamentos afetivos, os conflitos e as perdas. M. define saúde como "mente boa em corpo bom, a maioria das doenças hoje são psicossomáticas, as pessoas estão precisando tratar mais a mente do que o corpo. $O$ trabalho que gente faz lá é melhorar o interno, a sua mente, para melhorar a saúde. Sessenta por cento das pessoas do centro vão lá procurar melhorar a saúde.

\section{Os procedimentos terapêuticos no terreiro de Umbanda}

Uma série de procedimentos terapêuticos são utilizados nos terreiros como o uso de chás, banhos, da água fluidificada. Mas esses procedimentos só fazem sentido dentro de um contexto maior, que é o do acolhimento, o do atendimento individualizado mediante uma escuta atenciosa para com todas as áreas da vida do indivíduo, e das orientações dadas a partir do diálogo que a entidade tem com o consulente. 0 tratamento espiritual, as orientações e o uso do chá são compreendido como complementação do tratamento feito com os médicos.

No entanto, não existe um bom resultado no tratamento sem o comprometimento da própria pessoa com a mudança no estilo de vida, no comportamento causador da doença. A entidade espiritual do Preto-velho é figura central para o tratamento, ele é, por excelência, o acolhedor. Acolhimento, escuta, fraternidade estão presentes e são imprescindíveis para a promoção da saúde e tratamento das doenças. Para G.

O Preto-velho é o maior psicólogo, ele tem uma ternura, uma coisa especial. É como se de repente eu te empresto um pouco da minha força, eu te empresto um pouco da minha fé, é como se naquele momento o consulente ele passa a absorver um pouco daquilo que o povo do terreiro é. Não é só um passe, a gente se envolve com a pessoa.

Os procedimentos terapêuticos abrangem recursos ligados à natureza, as ervas, os chás, os banhos, a água, mas nada disto alcança eficácia se não houver o comprometimento do próprio indivíduo para com o tratamento. Ele tem que responsabilizar por si, pois os milagres não são fáceis de acontecer, como diz MM.: "A pessoa consegue uma graça de uma melho$r a$, mas tudo depende da pessoa, não adianta falar que nós vamos fazer um milagre, que nós não vamos fazer".

Por outro lado, a incompletude dos procedimentos terapêuticos realizados no terreiro está presente nas falas das lideranças quando reconhecem os limites de tratamento no terreiro, pois, dependendo da doença, os filhos de fé são encaminhados para o tratamento médico, como relata $\mathrm{R}$ : 
Tem doenças físicas que podem ser curadas por meio de banhos, chás e acompanhamento médico. Nunca um guia mandou a pessoa jogar o remédio fora e parar de ir ao médico, trabalhou junto. Quando chega aqui com um mal físico que precisa de um medicamento, tá, nós, os guias, sempre recomendamos a pessoa a procurar o médico.

Mas as terapias realizadas no terreiro auxiliam o médico em seus procedimentos, quando melhores resultados são conseguidos no tratamento que prescreve.

A concepção de saúde e doença veiculada pelos terreiros, assim como suas práticas, possue zonas de contato com o documento da OMS (2002), "Estratégia da OMS sobre medicina tradicional 20022005", que representou a primeira estratégia global para integração da Medicina Tradicional (MT) nos sistemas de saúde nacionais.

As terapias da MT são aquelas amplas e sistematicamente fundadas por anos de experiência e repassadas por meio da difusão oral de conhecimentos e práticas, podendo se embasar em sintomas físicos ou percebido pela atuação de forças sobrenaturais.

A Estratégia da OMS reconhece a incompletude dos saberes e práticas da medicina hegemônica apontando que outras formas de prevenção, promoção e tratamento da saúde podem ser encontradas em outros campos culturais, campos esses mais elásticos e que abrangem diversos aspectos do processo saúde-doença.

0 acolhimento também é enfatizado pelo Programa HumanizaSUS, que o define como: a recepção do usuário, desde sua chegada, responsabilizando-se integralmente por ele, ouvindo sua queixa, permitindo que ele expresse suas preocupações, angústias, e, ao mesmo tempo, colocando os limites necessários, garantindo atenção resolutiva, e a articulação com os outros serviços de saúde para a continuidade da assistência, quando necessário (Ministério da Saúde HumanizaSUS, 2006, p. 36).

Esses objetivos e definições é que se referem: ao acolhimento, à escuta atenciosa, à promoção do autocuidado, à integração do ser humano com o meio ambiente e a sociedade, à visão ampliada do processo saúde-doença que considera o físico, o mental e o espiritual, e são marcas dos procedimentos terapêuticos já realizados no terreiro de Umbanda e presente nas falas anteriormente destacadas das lideranças umbandistas. É necessário enfatizar se as lideranças entrevistadas estão cientes dos limites dos procedimentos realizados no terreiro: sabem até onde vai a intervenção espiritual, psicológica e fitoterápica, e onde que começa o tratamento pela medicina oficial, mas isto não se dá de forma excludente. Esses procedimentos podem andar juntos e de forma colaborativa.

Os discursos das lideranças entrevistadas apontam, pois, para uma outra forma de pensar a saúde e a doença, o que contribui para situar a Umbanda num lugar de referência cultural que legitima os saberes miscigenados, descoloniza os saberes hegemônicos, e constrói um topoi não etnocida.

\section{Considerações finais}

A Umbanda retoma questões coletivas relacionadas à opressão racial atuando como foco de resistência cultural e centro de difusão e troca de saberes. 0 corpo na Umbanda possui um lugar especial, pois ele é o elo de ligação com os espíritos ancestrais. É a partir do corpo dos médiuns que os espíritos passam suas mensagens para os seres humanos. Essa concepção permite que o corpo receba uma atenção especial o que se desdobra na compreensão da saúde, sempre compreendida de uma forma holística, global. A saúde compreende diferentes dimensões, todas integradas, e se referem à saúde mental, espiritual e física. Qualquer desequilíbrio em um desses campos provoca enfermidades. Essa visão viabiliza uma possível zona de contato entre a Umbanda e o princípio de integralidade em saúde do SUS quanto à necessidade de compreender o processo saúde-doença como tendo causas sociais e culturais, indo além da visão especializada da biomedicina.

A atenção do Preto-velho aos consulentes, a escuta, sua paciência e compreensão dos problemas humanos, suas orientações quanto aos tratamentos e mudanças no estilo de vida atuam no sentido do que o HumanizaSUS tanto anseia, e aqui uma outra possibilidade de diálogo se configura, oportunidade em que, de forma simbólica, a entidade teria muito o que ensinar aos médicos e equipes de saúde do SUS.

Dessa forma, os procedimentos terapêuticos utilizados nos terreiros - os chás, as ervas, a água, a crença em entidades sobrenaturais, a escuta das entidades, 0 acolhimento dos médiuns e cambones, a visão integralizada da saúde, condizem com o que é preconizado pela Organização Mundial da Saúde, conforme documentos apresentados. 
Considera-se, pois, com o presente estudo, que os terreiros de Umbanda são espaços potenciais de informação e educação em saúde, e por integrarem, em sua grande maioria, a população negra, tornam-se importantes centros de enfrentamento das doenças que atingem população. 0 desafio, pois, é buscar esse diálogo, entre as lideranças umbandistas e as equipes de saúde, para troca de conhecimento e expansão dos espaços de promoção de saúde.

\section{Referências}

Augra, M. (2003). O corpo nas religiões de matriz africana, 2003. In J. Marmo (Org.). Religiões afro-brasileiras e saúde (pp. 92-99). Maranhão: Centro de Cultura Negra.

Ferretti, M. (2003). Religiões afro-brasileiras e saúde: Diversidades e semelhanças. Boletim da Comissão Maranhense de Folclore, (25), 12-15.

Figueroa, A. (2004). Contextualização conceitual e histórica. In Anais do I Seminário Nacional de Saúde da População Negra, Caderno de textos básicos. Brasília: Seppir; Ministério da Saúde.

Foucault, M. (1985). Microfísica do poder. Rio de Janeiro: Graal.

Guimarães, M. A. (1990). É um umbigo, não é?: A mãe criadeira, um estudo sobre o processo de construção de identidade em comunidades de terreiro. Dissertação de Mestrado, Pontifícia Universidade Católica do Rio de Janeiro, Rio de Janeiro.

Laplantine, F. (1988). Os sistemas de representações da doença e da saúde na umbanda em Fortaleza. Comunicações do Iser, 7(30), 52-60.

Mattos, R. Integralidade é o próprio caminho, que vai transformando as pessoas e construindo algo melhor. BoletIN Integralidade em saúde do LAPPIS - Laboratório de Pesquisas sobre Práticas de Integralidade em Saúde. Recuperado em 6 abr. 2010, em http://www.lappis.org.br/cgi/cgilua.exe/sys/start. htm?infoid $=163 \&$ sid $=25$

Mignolo, W. D. (2003). Histórias locais/projetos globais. Colonialidade, saberes subalternos e pensamento liminar. Belo Horizonte: Ed. UFMG.
Ministério da Saúde. (2007). Secretaria de Gestão Estratégica e Participativa, política nacional de saúde integral da população negra. Recuperado em 6 abr. 2010, em http://bvsms.saude.gov.br/bvs/publicacoes/ politica_saude_integral_populacao_negra.pdf

Ministério da Saúde. (2010). Formação e intervenção. Cadernos HumanizaSUS, 1. Recuperado em 6 abr. 2010, em http://www.saude.ba.gov.br/images/Arquivos/ rede_cegonha/MANUAIS/humanizacao/cadernos_ humanizaSUS.pdf

Ministério da Saúde. Secretaria de Atenção à Saúde. Núcleo Técnico da Política Nacional de Humanização. (2006). Documento Base para Gestores e Trabalhadores do SUS. 3a. ed. Brasília: Editora MS.

Ministério da Saúde. (2006). Política Nacional de Práticas Integrativas e Complementares no SUS, atitude de ampliação de acesso. Brasília: Editora MS.

Ministério da Saúde. (2005). A saúde da população negra e o SUS: Ações afirmativas para avançar na equidade. Recuperado em 6 abr. 2010, em http://portal.saude.gov. br/portal/arquivos/pdf/caderno_spn.pdf

Montero, P. (1985). Da doença à desordem: A magia na Umbanda. Rio de Janeiro: Graal.

Municípios, cidades e comunidades saudáveis. Guia dos Prefeitos para promover qualidade de vida. In Organização Pan-Americana de Saúde. Recuperado em 25 nov. 2009, em http://www.opas.org.br/publicmo. cfm?codigo $=95$

Oliveira, F. Saúde da população negra. Brasília: OPAS, 2002.

Organización Mundial de la Salud. (2002). Estrategia de la OMS sobre medicina tradicional 2002-2005. Recuperado em 25 nov. 2009, em http://whqlibdoc. who.int/hq/2002/WHO_EDM_TRM_2002.1_spa.pdf

Santos, B. S. (2008). A gramática do tempo: Para uma nova cultura política. São Paulo: Cortez.

Silva, J. M. (2007). Religiões e saúde: A experiência da Rede Nacional de Religiões Afro-Brasileiras e Saúde. Revista Saúde e Sociedade, 16(2), 171-177. 